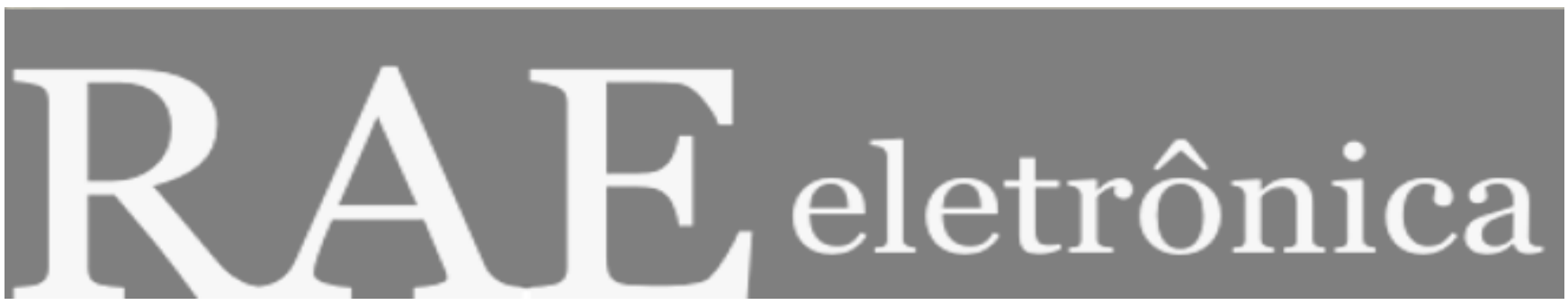

ORGANIZAÇÕES NO ESPAÇO CIBERNÉTICO:

ESTUDO COMPARATIVO ALTAVISTA E AMAZON BOOKS

Por:

Carlos Baldessarini Cano

João Luiz Becker

Henrique Mello Rodrigues de Freitas

RAE-eletrônica, Volume 1, Número 2, jul-dez/2002.

http://www.rae.com.br/eletronica/index.cfm?FuseAction=Artigo\&ID=1132\&Secao=INFORMAÇÃO\&Volume=1\&Numer $\mathrm{o}=2 \& A \mathrm{Ano}=2002$

CCopyright, 2002, RAE-eletrônica. Todos os direitos, inclusive de tradução, são reservados. É permitido citar parte de artigos sem autorização prévia desde que seja identificada a fonte. A reprodução total de artigos é proibida. Os artigos só devem ser usados para uso pessoal e não-comercial. Em caso de dúvidas, consulte a redação: redacao@,rae.com.br.

A RAE-eletrônica é a revista on-line da FGV-EAESP, totalmente aberta e criada com o objetivo de agilizar a veiculação de trabalhos inéditos. Lançada em janeiro de 2002, com perfil acadêmico, é dedicada a professores, pesquisadores e estudantes. Para mais informações consulte o site www.rae.com.br/eletronica.

RAE-eletrônica

ISSN 1676-5648

(C)2002 Editora: Fundação Getulio Vargas - Escola de Administração

de Empresas de São Paulo.

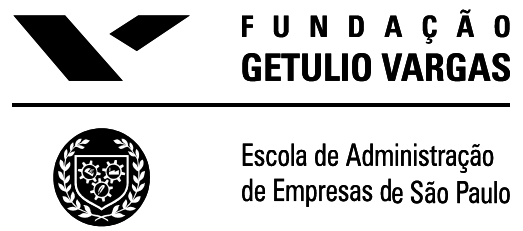




\title{
ORGANIZAÇÕES NO ESPAÇO CIBERNÉTICO: ESTUDO COMPARATIVO ALTAVISTA E AMAZON BOOKS
}

\section{Carlos Baldessarini Cano}

Mestre em Administração pelo PPGA/EA/UFRGS, Doutor em Administração pelo PPGA/EA/UFRGS e Professor Adjunto do Departamento de Ciências Administrativas da EA/UFRGS.

E-mail:ccano@ea.ufrgs.br

\section{João Luiz Becker}

Mestre em Matemática Aplicada pelo IMPA/CNPq, Doutor em Administração pela AGSM/UCLA, Professor Titular do Departamento de Ciências Administrativas da EA/UFRGS e Pesquisador do CNPq.

E-mail: jlbecker@ea.ufrgs.br

\section{Henrique Mello Rodrigues de Freitas}

Mestre em Administração pelo PPGA/EA/UFRGS, Doutor em Administração pela ESA/UPMFGrenoble, Professor Adjunto do Departamento de Ciências Administrativas da EA/UFRGS e Pesquisador do CNPq.

E-mail: hfreitas@ea.ufrgs.br

\section{RESUMO}

As organizações passam por mudanças revolucionárias ao incorporar potencialidades surgidas com a convergência tecnológica das indústrias de computação, telecomunicações e realidade virtual. A chamada organização virtual (OV) tem explorado, ao máximo, estas potencialidades, usando, em sua estruturação e operação, inovações tecnológicas que se traduzem, na prática, em características sui generis. Busca-se aqui a verificação da existência destas características peculiares, em organizações virtuais destaques no cenário empresarial. Dois casos são analisados: o serviço de buscas automáticas AltaVista e a livraria virtual Amazon Books. Para tal, elaborou-se um protocolo de análise englobando seis categorias analíticas: processos virtualizados, instalações físicas, atendimento ao cliente, fractalidade, confiança e aprendizado organizacional. Os dados foram coletados por observação direta nos "sites" das organizações, consultas específicas via correspondência, bancos de informações, literatura especializada e mídia em geral. Os resultados do estudo indicam claramente que as características investigadas estão presentes, formando a base operacional das empresas estudadas. O protocolo usado no estudo demonstrou o seu valor para analisar este novo tipo de organização.

\begin{abstract}
Organizations are currently facing revolutionary changes as they incorporate new communication and information technology as well as virtual reality. The so called virtual organization (VO) has explored these new potentialities to the maximum extent, basing its structure and operation on technological innovations that gives rise to truly sui generis characteristics. In this paper we seek to highlight these distinct characteristics studying two cases (Altavista and Amazon Books). We follow a specific analysis protocol with six analytical categories: virtual processes, physical installations, client services, fractality, trust and organizational learning. Data were gathered by direct observation on the corporations web sites, direct correspondence by mail and e-mail, data files, as well as technical literature and other media in general. Results clearly indicate the presence of the investigated characteristics,
\end{abstract}




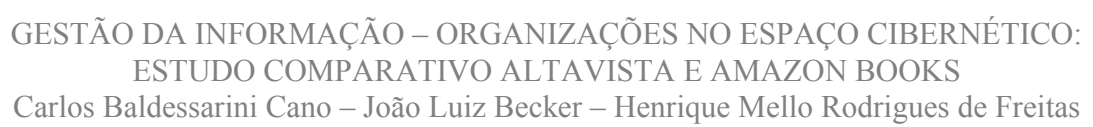

forming the operational base of the corporations analyzed. The protocol used in the study has proved its value to analyze this kind of organizations.

\section{PALAVRAS-CHAVE}

Espaço cibernético, organizações virtuais, estudo de caso.

\section{KEY WORDS}

Cyber space, virtual organizations, case study. 


\section{INTRODUÇÃO}

A convergência tecnológica das indústrias de computação, telecomunicações e realidade virtual, trouxe termos relacionados ao conceito de virtualidade: organização virtual $(\mathrm{OV})$, corporação virtual, firma virtual, escola virtual, biblioteca virtual, livro virtual, escritório virtual, cheque virtual, comunidade virtual, cidade virtual, arquivo virtual, museu virtual, café virtual, etc. Virtual parece ser um termo de moda, usado com vários entendimentos. A expressão OV está no centro deste redemoinho semântico.

Diversos pesquisadores, nacionais e estrangeiros, têm-se dedicado ao tema, embora o termo OV venha sendo utilizado de forma extremamente abrangente, havendo mesmo divergência entre autores (Davidow e Malone, 1993; Byrne e Brandt, 1993; Bjur e Caravantes, 1994; Davenport, 1995, Skyrme, 1995; Ridout, 1997; Thompson, 1997; Cano, Becker e Freitas, 1998). Neste artigo, usaremos a definição oferecida por Cano, Becker e Freitas (1998), que situam a OV no cenário das formas emergentes de organização e estruturação empresarial.

A chave para a compreensão do que é virtualidade depende do entendimento do efeito produzido por determinada entidade ou dispositivo. É necessário associar a entidade X com o efeito produzido por X, que podemos rotular como efeito $\mathrm{Y}$. Para outra entidade, distinta de $\mathrm{X}$, poder ser chamada de entidade "X virtual", ela deverá necessariamente produzir o mesmo efeito Y. Naturalmente, a complexidade do mundo faz com que a entidade $\mathrm{X}$ não produza unicamente o efeito $\mathrm{Y}$, provocando também, concomitantemente, vários outros efeitos Z, W, etc. Percebe-se assim uma das dificuldades semânticas existentes quando se fala em virtualização. A rigor, não poderíamos falar em entidade "X virtual" sem menção explícita ao efeito Y. O efeito focalizado (subjetivamente), Y, será definido como essência de X.

A atribuição da essencialidade a um dado efeito (por exemplo, Y) é resultado de uma valorização pessoal, dependente da própria visão de mundo de cada indivíduo. Assim sendo, uma mesma entidade ou dispositivo pode ter distintas essências, dependendo de quem os aprecia. Um livro pode ser percebido de diversas maneiras (efeitos produzidos Y, Z, W, etc.). Essencialmente, pode-se definir um livro como uma forma de representar e armazenar as idéias de seu autor (informação nele contida); dentre várias características, uma biblioteca pode ser vista como um repositório de informações (essência), representando e armazenando as idéias de vários autores; um cheque pode ser visto como uma particular forma de representar e armazenar a autorização ao banco para pagar determinada quantia a seu portador, debitando à conta corrente de seu emitente (informação nele contida).

Com o uso cada vez mais acentuado da Tecnologia da Informação, formas usuais de representação e armazenamento de informações têm sido substituídas por novas formas (com a manutenção da essência). Estas, quando comparadas fisicamente com as substituídas, são muito distintas, praticamente desprovidas de materialidade, de visibilidade. Fala-se em livro virtual, biblioteca virtual e cheque virtual. Vive-se uma era de acelerada virtualização, possibilitada e impulsionada pelos computadores os quais nos permitem explorar metáforas como nunca antes foi possível. Estas metáforas, nem sempre claras nas representações eficazes que as utilizam, mas sempre presentes na base da estrutura lógica destas representações, têm como elemento fundamental a noção de entidades virtuais.

O objetivo deste trabalho é aprofundar a análise da OV, desenvolvendo um modelo analítico e realizando estudos de caso em duas organizações em diferentes estágios de virtualização: o serviço de busca automática AltaVista (http://www.altavista.digital.com) e a Amazon Books (http://www.amazon.com). Objetiva-se verificar em que medida as propaladas características das OV 


\section{GESTÃO DA INFORMAÇÃO - ORGANIZAÇÕES NO ESPAÇO CIBERNÉTICO: ESTUDO COMPARATIVO ALTAVISTA E AMAZON BOOKS \\ Carlos Baldessarini Cano - João Luiz Becker - Henrique Mello Rodrigues de Freitas}

se fazem efetivamente presentes nestas organizações. O trabalho está organizado da seguinte maneira: na seção 2 apresenta-se o conceito de OV; na seção 3, o processo de virtualização; na seção 4 sintetizase a metodologia utilizada; na seção 5 os resultados são analisados e a seção 6 conclui o artigo.

\section{CONCEITO DE OV}

Em artigo recente, Cano, Becker e Freitas (1998) resgatam diversos conceitos e idéias inerentes ao tema, apresentando a seguinte definição:

"Uma OV é um arranjo sistêmico de entidades - homens, agentes autônomos, organizações (virtuais ou não), sistemas, bancos de dados, transdutores - que visa interligar e integrar dinamicamente, por meio de TI, demandas e recursos para sua satisfação, com regras de atuação estrategicamente definidas" (Cano, Becker, Freitas, 1998, p. 31).

Segundo os autores, uma OV cria uma matriz organizacional polidimensional, que interliga e integra dinamicamente demandas, recursos e regras de atuação, de forma precisa e confiável. As funções administrativas e de serviços são desempenhadas por humanos e por agentes não humanos, como outras organizações, bancos de dados, sistemas, programas, transdutores, etc., usando recursos informacionais diversos. A OV busca a virtuosidade, a excelência, e o faz buscando a essência de sua razão de ser, de seus processos e procedimentos, a virtude de provocar os efeitos desejados, procurando dissociar as necessidades abstratas de seus satisfatores físicos tradicionais, bem como de suas cadeias usuais de distribuição. A OV estrutura-se embasada em confiança, tanto em seus sistemas e processos, como no relacionamento com seus clientes, fornecedores e parceiros. Devido ao uso intenso de Tecnologia de Informação, tem suas fronteiras pouco definidas, explorando esta fraca definição para exteriorizar aquilo que contém em seus domínios, bem como para internalizar o que está fora de seus domínios.

Assim, pode-se imaginar a existência de organizações que se encontram e transacionam através de suas representações nos espaços cibernéticos. Benedikt (1994) condensa com precisão a idéia de espaço cibernético:

"Espaço cibernético é uma realidade virtual, ou artificial, multidimensional, globalmente trabalhada em rede, suportada por computadores, acessada por computadores, gerada por computadores. Nesta realidade, para a qual cada computador é uma janela, objetos vistos ou ouvidos não são nem físicos nem, necessariamente, representações de objetos físicos, mas são, principalmente, na forma, caráter e ação, formados por dados, por pura informação. Esta informação deriva em parte das operações do mundo físico, natural, mas a maior parte dela deriva do imenso tráfego de informações que constitui os empreendimentos humanos em ciência, arte, negócios e cultura” Benedikt (1994, p. 122).

As representações nos espaços cibernéticos são eficazes, pois produzem efeitos reais, cada vez mais prescindem do trabalho humano e têm sua disseminação impulsionadas pela tendência de zeramento dos custos operacionais envolvidos.

\section{PROCESSO DE VIRTUALIZAÇÃO}

Desconhece-se a existência de uma organização totalmente virtualizada, satisfazendo na íntegra a definição apresentada na seção anterior, pois sempre haverá uma base tecnológica concreta que lhe dê su- 


\section{GESTÃO DA INFORMAÇÃO - ORGANIZAÇÕES NO ESPAÇO CIBERNÉTICO: ESTUDO COMPARATIVO ALTAVISTA E AMAZON BOOKS \\ Carlos Baldessarini Cano - João Luiz Becker - Henrique Mello Rodrigues de Freitas}

porte. Pensar idealmente em uma OV pura é, entretanto, interessante sob o ponto de vista de análise. Na prática, verifica-se a existência de processos de virtualização em métodos de produção, em produtos de alto conteúdo informacional e mesmo em setores de atividade. Em conseqüência, as organizações apresentam-se em diferentes estágios de avanço em direção ao virtual.

O processo de virtualização conduz à substituição de entidades materiais por entidades virtuais, mantida a essência que as caracteriza. Esta definição ampla indica que este processo não é restrito à área de Administração, embora esta área, por sua interação com muitas outras áreas de atividades diferenciadas, tenha se tornado um dos principais focos de irradiação das influências e conseqüências advindas do reconhecimento deste novo paradigma.

A evolução dos níveis de virtualização propicia o ponto de apoio para alavancar a passagem da economia de capital para a economia da informação, pois provoca mudanças conceituais que apontam para um novo cenário empresarial, no qual novas possibilidades econômicas, sociais e culturais podem ser vislumbradas. Neste novo cenário, no qual quase tudo é possível, a desmaterialização traduz-se por um alto grau de liberdade de formas, ações e percepções.

Esta desmaterialização evidencia a separação entre o aspecto físico de um produto e sua função, como no exemplo do livro eletrônico. Os elementos físicos componentes do livro convencional (papel, tinta, cola) podem ser abstraídos, sem perda de sua essência, quando for usado o livro virtual. Com a perda de materialidade, novas possibilidades se abrem, no tocante à produção, transporte, distribuição, venda, leitura e edição. Com o avanço do processo de virtualização (ou desmaterialização), o cotidiano é afetado, desviando a atenção do mundo material para um mundo de símbolos e informações. Os símbolos, antes meras representações do mundo material, agora compõem o mundo virtual. Assim, o mundo virtual é feito de símbolos, imateriais em sua composição, mas eficazes no desempenho de funções. Reconhecemos a imaterialidade do livro virtual, mas também reconhecemos sua eficácia como fonte de informação.

Ao reconhecer explicitamente a distinção entre os requisitos funcionais da demanda e os meios que a satisfarão, abre-se um campo de exploração que visa a encontrar novos meios de satisfazer antigas demandas, mantendo a essência. Neste artigo, este é o ângulo mais representativo do processo de virtualização, pois implica diretamente a criação de novos processos produtivos e administrativos. Por exemplo, se a demanda é gerada por jogadores que querem apostar em um cassino, uma forma convencional seria levá-los até lá fisicamente, onde encontrariam equipamentos de jogos e uma equipe para conduzir as apostas. A Tecnologia da Informação disponível hoje permite que o cassino (virtual) seja levado ao jogador (demandante) e assim atender virtual e suficientemente ao anseio que propiciou a transação. Claro está que aquele jogador que julga importante as luzes, a música, o brilho e o charme de um cassino convencional, poderá não se satisfazer com a solução proposta. Mas outros sentir-se-ão satisfeitos, a ponto de aceitar o serviço. Muitos de nós preferimos o contato, o cheiro, a presença física de um livro, mas uma visão objetiva pode nos levar a aceitar o livro virtual, via biblioteca virtual, como uma fonte suficientemente eficaz de conhecimento.

Assim, tanto quanto prospectar entidades capazes de satisfazer as necessidades de seus clientes (definidas em termos abstratos), cabe à administração da OV investigar possíveis novos meios de satisfazêlas, mesmo que isto represente uma alteração de hábitos ou mesmo de cultura. Os espaços cibernéticos têm facilitado a criação e aceitação de novos meios de satisfazer antigas necessidades, bem como de gerar necessidades novas para serem atendidas por novas formas de serviços. Na primeira categoria 


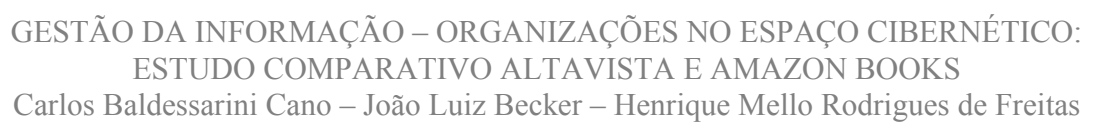

(novos meios de atender a necessidades existentes), os exemplos são abundantes: a biblioteca virtual, o cassino virtual, o museu virtual, o "e-mail”, entre outros. Na segunda (geração de novas necessidades), encontram-se a pesquisa global através dos "browsers" (como o http://www. altavista.com), a crescente exigência de visualização gráfica e o teletrabalho, por exemplo. Além disto, os espaços cibernéticos têm permitido o refinamento de requisitos de necessidades já existentes, de tal forma que pareçam novas necessidades, como o produto individualizado ao alcance da massa consumidora (calças, carros e livros personalizados, entre outros). Já é possível a adoção de estratégias mercadológicas inéditas, como a atomização (nicho de um só) em massa. É inegável que a substituição dos meios físicos de satisfação de necessidades abstratas por meios virtuais pode ser sentida em toda a vida moderna, em todas as camadas da população.

Mais especificamente sob o foco da Administração, o processo de virtualização indica novas formas de organizar, substituindo entidades materiais das estruturas organizacionais convencionais por entidades virtuais. A intensidade desta substituição aproxima a realidade ao arcabouço teórico aqui denominado de OV. Este processo não tem uma seqüência definida, depende de fatores mercadológicos, tecnológicos e culturais. Algumas organizações tirarão da virtualização o maior proveito, enquanto outras manter-se-ão à margem deste processo, ignorando-o ou sendo por este atropeladas.

O processo de virtualização não apresenta regras fixas, seqüências estabelecidas e uma dimensão final uniforme (Venkatraman, apud Sorensen, 1997; Sieber, 1997; McKinney e Gerloff, 1997; Riggins e Rhee, 1997). Como conseqüência dessa falta de uniformidade, organizações com diferentes graus de virtualização convivem no mercado, muitas vezes no mesmo setor empresarial. Este artigo analisa duas organizações, a Amazon Books e o AltaVista, com estruturas distintas e diferentes graus de virtualização. Olhadas convencionalmente, cada uma destas organizações tem atividade econômica distinta, atuando em segmentos mercadológicos diferentes. Olhadas mais amplamente, as duas empresas dedicam-se à organização e distribuição da informação. Dentro de um cenário marcado por desigualdades, parece haver uma convergência para algumas formas de organizar, estrategicamente definidas e bastante diferentes entre si. Como se depreende dos resultados do estudo de caso realizado (adiante detalhado), a Amazon Books já surgiu virtual em suas vendas e, provavelmente, jamais assumirá uma estruturação convencional, com lojas físicas, atendentes humanos e um longo balcão, com clientes fazendo suas escolhas dentre milhões de títulos. Por outro lado, o AltaVista é o serviço de pesquisa pioneiro, que revolucionou o uso da Internet (Ray et al., 1998). Os serviços de pesquisa não têm similares convencionais próximos em velocidade, precisão, volume de atendimento e proximidade ao cliente. $\mathrm{O}$ serviço de pesquisa AltaVista trabalha com alto nível de automação e uso intenso de robôs e hoje é um dos portais de maior tráfego na rede. Tem desenvolvido seus sistemas de busca e recuperação, facilidade que tem se traduzido em uma situação de ponta no mercado, mantida por um fluxo contínuo de inovações. A escolha do serviço de pesquisa AltaVista também é justificada como sendo o caso que, à primeira vista, mais fortemente pode ser identificado com o modelo de análise proposto. Assim, poderia vir a corroborar a validade empírica do arcabouço teórico montado.

\section{METODOLOGIA}

A principal preocupação motivadora deste artigo está relacionada (1) ao espaço cibernético e suas características; (2) à OV e suas características; (3) à montagem de um modelo para análise da OV e (4) à verificação de sua aplicabilidade e adequação, a campo. 


\section{GESTÃO DA INFORMAÇÃO - ORGANIZAÇÕES NO ESPAÇO CIBERNÉTICO: ESTUDO COMPARATIVO ALTAVISTA E AMAZON BOOKS \\ Carlos Baldessarini Cano - João Luiz Becker - Henrique Mello Rodrigues de Freitas}

A fase teórica deste trabalho compreendeu uma extensa compilação de conhecimentos existentes sobre o tema genérico da virtualização das estruturas organizacionais e das possibilidades que o atual estágio tecnológico propicia. Esta fase teórica pode ser descrita por três atividades principais, que centralizaram a busca dos objetivos propostos.

A primeira atividade realizada buscou identificar as características mais marcantes do espaço cibernético, e que poderiam ser úteis para a montagem de uma nova forma de organização. Estas possibilidades foram definidas por observação e por conjectura, visto que nem todas estão claramente reveladas, mas podem ser deduzidas e imaginadas. Além disto, como o modelo seria posteriormente testado à luz da realidade dos fatos, o interesse maior foi de elencar um bom número de possibilidades, as mais inovadoras possíveis.

De posse das possibilidades do espaço cibernético, a segunda atividade realizada foi tentar a operacionalização das mesmas, isto é, como poderiam ser traduzidas para a realidade dos empreendimentos e como poderiam ser inseridas em uma estrutura organizacional e funcional ativa. Em conjunto, as propriedades estruturais e operacionais foram descritas como características das organizações que exploram as potencialidades do espaço cibernético, por operarem neste ambiente.

A terceira atividade consistiu em reunir as características identificadas em um modelo ideal, que servisse para análise de uma estrutura adaptada ao espaço cibernético. Neste trabalho, tal estrutura tem sido chamada de OV. Esta reunião de funcionalidades projetadas produziu o modelo teórico para análise da OV, sintetizado no quadro 1, a seguir.

\section{Quadro 1: Categorias analíticas investigadas}

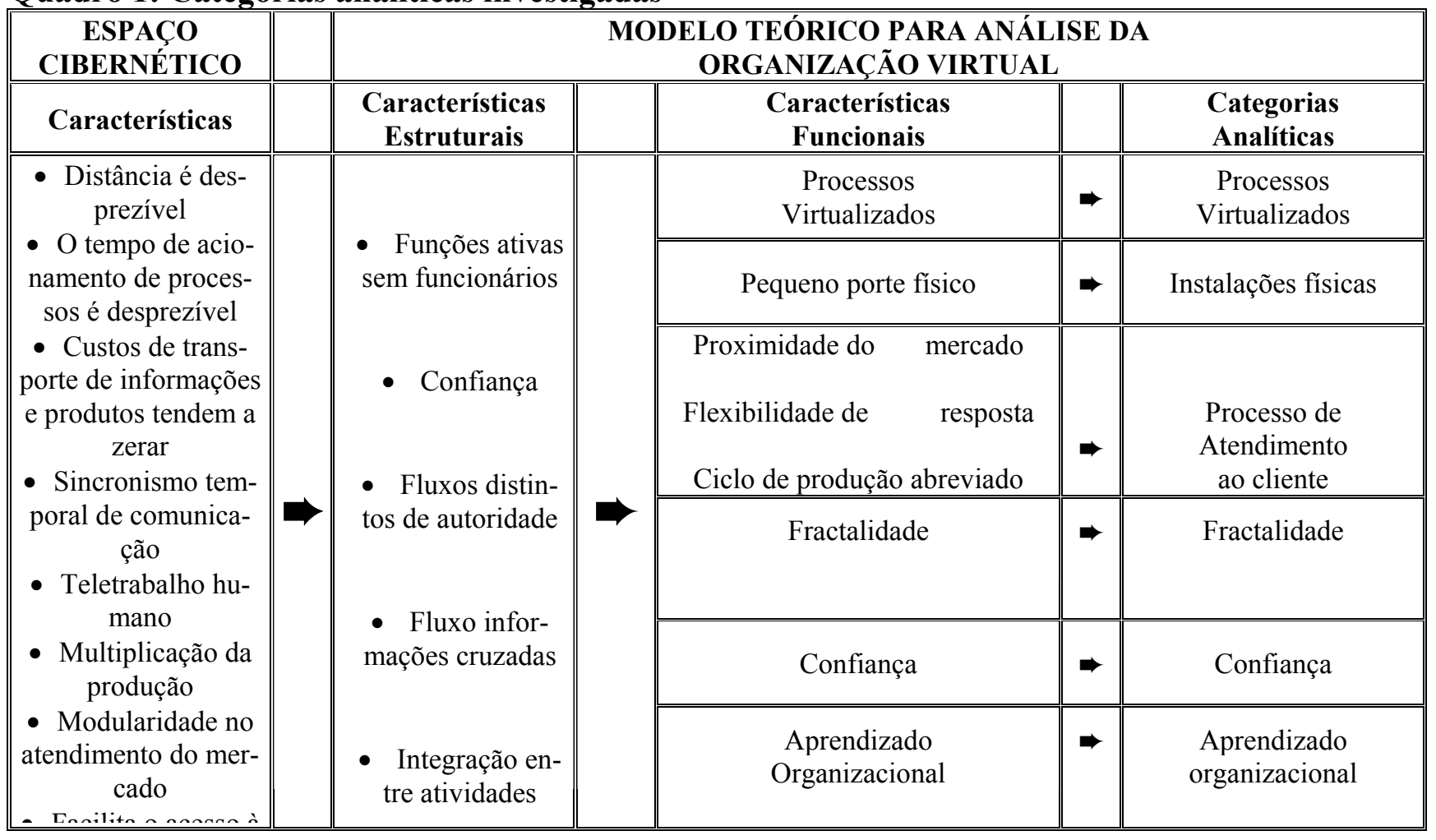




\section{GESTÃO DA INFORMAÇÃO - ORGANIZAÇÕES NO ESPAÇO CIBERNÉTICO: ESTUDO COMPARATIVO ALTAVISTA E AMAZON BOOKS \\ Carlos Baldessarini Cano - João Luiz Becker - Henrique Mello Rodrigues de Freitas}

Para definir como seria atingida a verificação empírica da aplicabilidade e adequação do modelo de análise sugerido, conforme os objetivos firmados, foi feita uma revisão da literatura sobre métodos de pesquisa, apontando como método mais adequado, um estudo de caso múltiplo (Yin, 1994).

Segundo Pozzebon e Freitas (1997), o estudo de caso é particularmente adequado ao exame exploratório de fenômenos ainda pouco estudados e que precisam ser analisados em seu meio ambiente de ocorrência, isto é, em seu habitat natural. Benbasat, Goldstein e Mead (1987) apontam três razões principais, justificando o emprego do estudo de caso em que sistemas de informação são parte importante do contexto. Primeiro, o pesquisador tem a oportunidade de aprender sobre o estado da arte, gerar novas teorias apoiadas na prática, pois estará efetuando o estudo do fenômeno em seu ambiente natural de ocorrência. Segundo, possibilita ao pesquisador entender a natureza e complexidade do processo enquanto este acontece. Perguntas do tipo "como?" e "por quê?" poderão ser respondidas com maior precisão. Terceiro, a forte dinâmica, característica do campo de sistemas de informação, pode trazer novos fatos e informações, só evidenciados durante a execução do processo estudado.

Como poucos estudos atualizados estão disponíveis, o estudo de caso parece ser o método mais indicado para registrar as mudanças ocorridas e em emergência. A seguir, é detalhado o projeto do estudo de caso múltiplo julgado adequado aos objetivos propostos.

\section{Definição do campo de pesquisa}

Fazendo parte dos objetivos do trabalho, a identificação de características inovadoras de estruturação organizacional e de novas formas de operação possivelmente consolidadas numa forma emergente de organização, só possível dentro de um espaço cibernético, o campo de pesquisa fícou necessariamente definido como sendo o de um espaço cibernético. Muitos são os espaços cibernéticos existentes adequados a esta pesquisa, por exemplo grandes redes de bancos e de bolsas de valores, redes de universidades, entre outras. Entretanto, devido ao seu tamanho, abrangência e atualidade, o espaço cibernético escolhido foi a Internet.

\section{Questão central de pesquisa}

Escolhido o campo de pesquisa e tendo em vista o objetivo principal - elaborar e testar um modelo para análise de organizações que operem em espaço cibernético - restou a verificação empírica de sua aplicabilidade e adequação, objeto da questão central de pesquisa:

\section{O modelo proposto permite analisar organizações com distintos níveis de inserção no Espaço Cibernético?}

A resposta a esta questão de pesquisa foi buscada em um estudo de caso múltiplo, envolvendo duas organizações: serviço de pesquisa AltaVista e a livraria virtual Amazon Books. Definida e explicitada a questão de pesquisa, foi estabelecido o delineamento dos procedimentos. 


\section{Definição do tipo de pesquisa}

A pesquisa é "cross-sectional", pois o interesse repousa principalmente nas características estruturais e operacionais que a organização apresenta no momento do estudo.

\section{Seleção das unidades de análise}

A unidade de análise é a organização, buscada em seu meio ambiente. Para tal, foi necessário realizar estudos das organizações enquanto inseridas em seu cenário operacional, seja este físico ou virtual. A partir do pressuposto de que a OV ainda é um estereótipo, não existente na forma pura (totalmente virtual), mesmo quando a análise é feita a partir de sua presença virtual, também os componentes físicos podem ser estudados. Dois casos são apresentados: o serviço de pesquisa AltaVista e a livraria virtual Amazon Books. O AltaVista é o serviço de pesquisa pioneiro, que revolucionou o uso da Internet (Ray et al., 1998). Os serviços de pesquisa não têm similares convencionais próximos em velocidade, precisão, volume de atendimento e proximidade ao cliente. O serviço de pesquisa AltaVista trabalha com alto nível de automação e uso intenso de robôs e hoje é um dos portais de maior tráfego na rede. Tem desenvolvido seus sistemas de busca e recuperação, facilidade que tem se traduzido em uma situação de ponta no mercado, mantida por um fluxo contínuo de inovações. A escolha do serviço de pesquisa AltaVista também é justificada como sendo o estudo de caso que mais fortemente pode ser identificado com o modelo de análise proposto. Assim, poderia vir a corroborar a validade empírica do arcabouço teórico montado.

A livraria virtual Amazon Books pretende disputar o primeiro lugar em vendas de livros (e mais recentemente CDs, presentes, utilidades, etc.) em um mercado altamente globalizado. Tem se mostrado ágil, correta em seus procedimentos, inspirando confiança a seus usuários. Também tem sido eficaz na procura, seleção e recomendação de obras de interesse variado. Para este estudo de casos, traz uma característica interessante: é uma livraria que só operou no espaço cibernético, não partiu de uma livraria convencional.

Ao combinar os dois casos propostos, pretendeu-se verificar em que medida ou de que forma as organizações enquadram-se no modelo proposto.

\section{Definição dos métodos de coleta de dados}

Foram utilizados diversos métodos de coleta de dados, tais como investigação interativa dos "sites", análise de documentos, revisão de bibliografia, entrevistas e testes de transações. O objetivo foi analisar de forma abrangente e profunda as unidades de pesquisa selecionadas, visando extrair o máximo de informações que subsidiem os objetivos da pesquisa.

\section{Protocolo para a realização dos estudos de caso}

Segundo Yin (1994), o essencial de um protocolo de estudo de caso é um conjunto de questões substantivas que permite analisar a questão central do estudo, no caso, como a OV funciona. Estas questões são colocadas para o pesquisador, não para os respondentes. São, na sua essência, lembretes que devem guiar a coleta de dados e informações. 


\section{ANÁLISE DOS RESULTADOS}

Inicialmente, são apresentadas algumas informações sobre as organizações pesquisadas.

O AltaVista resulta de um projeto ambicioso, quase impensável há alguns anos: indexar e facilitar o acesso às informações contidas em toda a Internet. No dia 15 de dezembro de 1995, o serviço de busca foi aberto ao público, com mais de trezentos mil acessos. Nove meses mais tarde, os acessos diários chegavam a dezenove milhões. Milhares de artigos apareceram, contando experiências individuais e compartilhando o entusiasmo da descoberta. Relatos foram feitos em jornais e revistas sobre o serviço de busca AltaVista. Finalmente, qualquer usuário que tivesse acesso a um "browser" na Internet teria um modo fácil de achar qualquer informação existente na rede. Inicialmente instalada em Palo Alto, a organização viu-se obrigada, devido ao crescimento acelerado de sua popularidade, a espelhar o serviço em outras localidades, geograficamente dispersas, formando uma rede de "sites" para a Europa do Norte, Europa do Sul, América Latina, Austrália e Ásia, chamada Rede de Busca AltaVista. Ao mesmo tempo em que o AltaVista se firma como um serviço público de busca e recuperação de informações, totalmente gratuito para o usuário, tem se mostrado um crescente sucesso de venda de serviços e produtos. É, hoje, um dos mais conhecidos integrantes do crescente cenário empresarial na Internet.

A Amazon Books é resultado da criatividade e esforço do seu fundador, Jeffrey Bezos, um dos pioneiros em vendas ao consumidor pela Internet. Trata-se de uma livraria virtual com milhões de títulos disponíveis, que podem ser pesquisados por autor, assunto, título, palavra-chave, editora, data de edição, ou conforme a faixa etária do público alvo (para crianças, por exemplo). Jeff estudou minuciosamente os detalhes de seu projeto, antes de abrir a loja. Inicialmente ele fez uma lista dos 20 produtos mais apropriados para serem vendidos na Internet, desde roupas até ferramentas de jardinagem, chegando a uma lista dos "cinco mais": CDs, vídeos, hardware, software e livros. Uma gama de critérios foi utilizada para chegar a este resultado, entre eles o tamanho do mercado de cada produto: o de livros movimentava US\$ 82 bilhões no mundo todo (Success, julho de 1998), bem como o preço. Jeff queria vender um produto barato. Outro fator preponderante foi o poder de escolha que os clientes teriam, graças à grande variedade de títulos (Success, julho de 1998). Em julho de 1995, a Amazon Books, auto-intitulando-se "a maior livraria do mundo", abriu suas portas na World Wide Web, com mais de um milhão de títulos em oferta, e somente 500 best-sellers em estoque. Raramente uma livraria tradicional oferece mais de cem mil títulos. Por ser a pioneira na venda de livros “on-line”, e pelos seus esforços dirigidos principalmente à satisfação de seus clientes, a Amazon é considerada uma empresa-guia para o comércio na Internet.

A seguir, os resultados da aplicação do protocolo são analisados, por categoria analítica (ver quadro 1) e questionamentos.

\section{Processos virtualizados}

A identificação de processos virtualizados é um ponto-chave na caracterização de uma OV. Em uma organização tradicional, o cliente geralmente precisa se deslocar e contatar diferentes pessoas a fim de obter o produto ou serviço desejado. Ele deve ir até a empresa, solicitar auxílio de um vendedor, examinar os produtos e serviços oferecidos, efetuar a compra, fazer o pagamento e retirar o produto comprado. 


\section{GESTÃO DA INFORMAÇÃO - ORGANIZAÇÕES NO ESPAÇO CIBERNÉTICO: ESTUDO COMPARATIVO ALTAVISTA E AMAZON BOOKS \\ Carlos Baldessarini Cano - João Luiz Becker - Henrique Mello Rodrigues de Freitas}

No AltaVista o atendimento ao cliente, a formação dos resultados e a sua distribuição são todos processos virtualizados. É o cliente quem senta em frente ao terminal do computador, entra no "site" da organização, efetua suas pesquisas e analisa os resultados, sem sair do lugar e sem estabelecer nenhum contato humano, não havendo ninguém para auxiliá-lo, a não ser programas de computador. A recuperação de informações, que é o principal serviço oferecido pelo AltaVista, também é um processo virtualizado: o Scooter percorre a Web, recupera informações, e as remete ao sistema de indexação (Vista), que compila o índice.

À semelhança do AltaVista, os processos de atendimento ao cliente e venda da Amazon são virtualizados. O cliente entra no "site", pesquisa livros, CDs e artigos eletrônicos (divididos em categorias distintas) e faz seu pedido. Por fim, o pagamento é feito por cartão de crédito, com dados criptografados para maior segurança do cliente. No entanto, o processo de distribuição do produto continua sendo físico, via correio.

$\mathrm{Na}$ área de recursos humanos do AltaVista, o processo de seleção de pessoal também é parcialmente virtualizado, pois a empresa mantém uma seção no seu "site" com anúncios de empregos, chamada "Our Job Openings" (http://www.altavista.com/av/ content/jobs.htm). A Amazon também mantém em seu "site" um espaço para anúncios de empregos, exigindo pessoas inovadoras e que gostem de desafios.

No que diz respeito ao controle, este não é percebido como algo à parte, em ambas as organizações pesquisadas. O controle está totalmente integrado aos procedimentos dos sistemas, "on-line" e em tempo real. Deste modo, inibe a ocorrência de erros, dando ao processo um alto grau de confiabilidade, prontamente percebido pelo cliente.

A rotina diária é altamente automatizada, não exigindo interferência constante dos administradores, que somente intervêm nas estratégias de marketing e vendas ou ocasionalmente, para correção de rota.

De uma maneira geral, ambas as organizações têm obtido excelente aceitação. O AltaVista é um dos "sites" de busca mais populares dos Estados Unidos e do mundo, sendo um dos principais portais da rede. No Natal de 1998, a Amazon bateu seu recorde de vendas de livros e a tendência é que os consumidores continuem comprando. A organização tornou-se uma referência no mercado de comércio eletrônico, tendo suas ações apresentado momentos de boa valorização na bolsa. No entanto, do ponto de vista dos lucros, a empresa ainda não recuperou o investimento feito. A Amazon amargou um prejuízo de US\$ 162 milhões para um faturamento de US\$ 774 milhões em 1998, devido aos altos investimentos feitos em tecnologia e marketing (Exame, março de 1999 - relatório da bolsa de NY). O quadro 2 resume as observações realizadas com referência à categoria analítica "processos virtualizados". 


\begin{tabular}{|l|l|l|l|}
\multicolumn{4}{|c|}{ Quadro 2: Processos virtualizados nas OV } \\
\hline \multicolumn{1}{|c|}{ ITEM } & \multicolumn{1}{|c|}{$\begin{array}{c}\text { CASO } \\
\text { ALTAVISTA }\end{array}$} & \multicolumn{1}{|c|}{$\begin{array}{c}\text { CASO } \\
\text { AMAZON }\end{array}$} & OBSERVAÇÕES \\
\hline \multicolumn{4}{|c|}{ Processos virtualizados } \\
\hline $\begin{array}{l}\text { Quais processos a- } \\
\text { presentam-se virtu- } \\
\text { alizados? }\end{array}$ & $\begin{array}{l}\text { Atendimento ao } \\
\text { cliente, pesquisa, } \\
\text { distribuição do } \\
\text { produto, recruta- } \\
\text { mento de RH }\end{array}$ & $\begin{array}{l}\text { Atendimento ao } \\
\text { cliente, pesquisa, } \\
\text { venda, recrutamen- } \\
\text { to de RH }\end{array}$ & $\begin{array}{l}\text { Boa parte dos pro- } \\
\text { cessos são virtuali- } \\
\text { zados, mas nenhu- } \\
\text { ma organização é } \\
\text { totalmente virtual }\end{array}$ \\
\hline $\begin{array}{l}\text { Como ocorre o } \\
\text { controle destes pro- } \\
\text { cessos? }\end{array}$ & $\begin{array}{l}\text { O controle é inte- } \\
\text { grado ao sistema e } \\
\text { impede a ocorrên- } \\
\text { cia de erros }\end{array}$ & $\begin{array}{l}\text { O controle é inte- } \\
\text { grado ao sistema e } \\
\text { impede a ocorrên- } \\
\text { cia de erros }\end{array}$ & $\begin{array}{l}\text { Os processos são } \\
\text { automatizados, ge- } \\
\text { rando grande con- } \\
\text { fiabilidade }\end{array}$ \\
\hline $\begin{array}{l}\text { Quando a direção } \\
\text { intervém? }\end{array}$ & $\begin{array}{l}\text { A direção intervém } \\
\text { ocasionalmente }\end{array}$ & $\begin{array}{l}\text { A direção intervém } \\
\text { ocasionalmente }\end{array}$ & $\begin{array}{l}\text { Não há necessidade } \\
\text { de intervenções ro- } \\
\text { tineiras }\end{array}$ \\
\hline $\begin{array}{l}\text { O empreendimento } \\
\text { tem tido sucesso no } \\
\text { mercado? }\end{array}$ & $\begin{array}{l}\text { Sim, é um dos "si- } \\
\text { tes" de busca mais } \\
\text { populares da rede }\end{array}$ & $\begin{array}{l}\text { Sim, a empresa ba- } \\
\text { teu seu recorde de } \\
\text { vendas no último } \\
\text { Natal }\end{array}$ & $\begin{array}{l}\text { O mercado eletrô- } \\
\text { nico apresenta alta } \\
\text { taxa de crescimento }\end{array}$ \\
\hline
\end{tabular}

\section{Instalações físicas}

$\mathrm{Na}$ medida em que os processos em uma OV são virtualizados, suas instalações tendem a ser reduzidas ao mínimo. A central de operações do AltaVista situa-se no Network Systems Laboratory, em Palo Alto. Em uma grande sala permanentemente refrigerada e monitorada, encontram-se os computadores que recebem as buscas, processam e indexam os dados e enviam os resultados para os usuários (Ray et al., 1998).

A principal função operacional abrigada nestas instalações é a manutenção do indexador de acesso às informações da Internet. Este índice é criado pelo rastreador de rede, chamado Scooter, que percorre a Internet coletando informações de aproximadamente 10 milhões de páginas por dia. O Scooter traz as páginas e as passa para o NI2, o "software" de indexação, que indexa cada palavra de cada página. O "software" guarda cada forma de aparecimento de cada palavra, inclusive formas com diferentes grafias (maiúsculo, por exemplo), o URL da página em que aparece, bem como algumas informações sobre sua localização no documento. O "software" também indexa palavras contendo caracteres não latinos, usando letras equivalentes em inglês. São estes detalhes que permitem a pesquisa de palavras individuais, frases nas quais a ordem das palavras seja essencial, e palavras ou frases com grafias específicas ou acentos.

De outra parte, a Amazon possui três grandes depósitos (o maior deles tem $28.000 \mathrm{~m}^{2}$ no estado de Nevada) e uma sede administrativa em Seattle. A função dos depósitos é armazenar as mercadorias. Construir mais depósitos faz parte dos planos da empresa, que pretende afastar-se cada vez mais da distribuidora Ingram, para comprar diretamente das editoras (Exame, março de 1999). O principais equipamentos são os computadores que contêm os pedidos e os dados cadastrais de cada cliente da Amazon. O quadro 3 sintetiza os resultados obtidos para a categoria analítica "instalações físicas". 
Quadro 3: Instalações físicas nas OV

\begin{tabular}{|c|c|c|c|}
\hline ITEM & $\begin{array}{c}\text { CASO } \\
\text { ALTAVISTA }\end{array}$ & CASO AMAZON & OBSERVAÇÕES \\
\hline \multicolumn{4}{|c|}{ Instalações físicas } \\
\hline $\begin{array}{l}\text { Qual o porte das } \\
\text { instalações físicas? }\end{array}$ & $\begin{array}{l}\text { Pequeno, junto ao } \\
\text { Network Systems } \\
\text { Laboratory em Palo } \\
\text { Alto, Califórnia, } \\
\text { EUA }\end{array}$ & $\begin{array}{l}\text { Grande, são três } \\
\text { grandes depósitos e } \\
\text { uma sede adminis- } \\
\text { trativa em Seattle }\end{array}$ & $\begin{array}{l}\text { Para o produto vir- } \\
\text { tual, o porte é pe- } \\
\text { queno; para o pro- } \\
\text { duto convencional, } \\
\text { o porte é conven- } \\
\text { cional }\end{array}$ \\
\hline $\begin{array}{l}\text { Quais funções estas } \\
\text { instalações abri- } \\
\text { gam? }\end{array}$ & $\begin{array}{l}\text { Manutenção do in- } \\
\text { dexador de acesso } \\
\text { às informações da } \\
\text { rede }\end{array}$ & $\begin{array}{l}\text { Armazenar as mer- } \\
\text { cadorias e o banco } \\
\text { de dados dos clien- } \\
\text { tes }\end{array}$ & $\begin{array}{l}\text { Em ambas, a fun- } \\
\text { ção principal é o } \\
\text { manuseio de seus } \\
\text { produtos (numa } \\
\text { virtual, noutra con- } \\
\text { vencional) }\end{array}$ \\
\hline $\begin{array}{l}\text { Quais os principais } \\
\text { equipamentos ins- } \\
\text { talados? }\end{array}$ & $\begin{array}{l}\text { Interface de pes- } \\
\text { quisa, mecanismo } \\
\text { de pesquisa, rastre- } \\
\text { ador, indexador da } \\
\text { rede, indexador e } \\
\text { servidor de notícias }\end{array}$ & $\begin{array}{l}\text { Os computadores } \\
\text { que contêm os da- } \\
\text { dos cadastrais, pre- } \\
\text { ferências e pedidos } \\
\text { de cada cliente da } \\
\text { Amazon }\end{array}$ & $\begin{array}{l}\text { As informações } \\
\text { contidas em um } \\
\text { computador desem- } \\
\text { penham um papel } \\
\text { fundamental em u- } \\
\text { ma OV }\end{array}$ \\
\hline
\end{tabular}

\section{Atendimento ao cliente}

Dentro de uma OV não há vendedor, nem atendente, nem gerente - o cliente deve efetuar todas as etapas da transação sozinho. A grande preocupação desse tipo de organização é tornar o seu "site" e o seu atendimento agradáveis e eficazes aos olhos do cliente.

Ao entrar no "site" do AltaVista, o cliente encontrará as ferramentas que precisa para realizar pesquisas simples ou avançadas, ou navegar para outras partes do serviço da empresa. O cliente decide se quer restringir a procura para uma só linguagem, ou todas, se preferir.

O AltaVista trará os resultados da pesquisa, indicando quantas páginas na Internet foram encontradas. Estes resultados estão dispostos um abaixo do outro e contêm informações úteis, tais como: o título de cada item, um pequeno trecho do documento, o endereço na rede ("link" para a página), o tamanho do documento, data em que o mesmo foi modificado, idioma, opção de tradução do arquivo. O cliente pode refinar sua pesquisa, a fim de obter melhores resultados e tornar a pesquisa menos cansativa (Ray et al., 1998).

Ao entrar na página principal da Amazon, o cliente já cadastrado será saudado com uma mensagem personalizada. Na página principal da Amazon encontram-se os últimos lançamentos de produtos, bem como notícias variadas. Bem no topo e bem no pé da página, encontram-se os "links" para as seguintes seções: livros, música, vídeo, presentes e "auctions". Se o usuário decide entrar em qualquer uma destas seções, ele recebe um "carrinho de compras", onde irá colocar todos os produtos que deseja adqui- 


\section{GESTÃO DA INFORMAÇÃO - ORGANIZAÇÕES NO ESPAÇO CIBERNÉTICO: ESTUDO COMPARATIVO ALTAVISTA E AMAZON BOOKS \\ Carlos Baldessarini Cano - João Luiz Becker - Henrique Mello Rodrigues de Freitas}

rir. Por exemplo, se ele entrar na seção "música", ele terá a possibilidade de navegar entre 14 estilos principais e 272 subgêneros e verificar quais os CDs mais vendidos ou comentados na mídia, entre outros serviços que a empresa oferece. E quando tiver completado o seu pedido, ele entrará em uma página de confirmação do mesmo, onde figuram os seus dados pessoais, parte do número do cartão de crédito, itens adquiridos, preço dos produtos e valor do frete. Depois que o cliente tiver realizado a compra, o sistema mostrará uma tela indicando o sucesso da operação e o número do pedido. Após, se quiser, o cliente poderá acompanhar o andamento do seu pedido, na seção "Your Account".

Enquanto o AltaVista utiliza apenas os recursos de Internet na comunicação com seus clientes, a Amazon, além destes, utiliza também o correio e o fax.

A principal característica da operação de atendimento ao cliente de ambas as organizações é a facilidade de acesso, bastando um computador ligado à Internet. Além disto, caracterizam-se por uma elevada velocidade de resposta, oferecida em frações de segundos, grande interatividade, dinamismo e abrangência. Os "sites" são ricos em imagens, "links" e fáceis de usar.

Quanto ao ciclo de produção, constata-se que a pesquisa no AltaVista pode tomar menos tempo do que localizar um arquivo num computador de uso pessoal. O tempo de resposta é medido em frações de segundos. Alguma demora adicional percebida pelo usuário pode ser decorrência de sua localização, de seu provedor, da qualidade da linha, dos equipamentos utilizados, etc. Por outro lado, na Amazon, o ciclo de produção depende da disponibilidade do item em questão e o tempo de entrega. A disponibilidade de grande parte dos itens é de 24 horas, sendo que o tempo de entrega leva em conta a região (www.amazon.com/exec/obidos/subst/help/shipping-policy-n...).

Conforme salientam Peppers e Rogers (1997), a entrega fora dos Estados Unidos é muitas vezes proibitiva em termos de custo.

Uma das preocupações dos pesquisadores ao realizar os estudos de caso era perceber se a funcionalidade de atendimento não fica prejudicada quando este é demandado por um grande número de usuários. O AltaVista é acessado em média 40 milhões de vezes por dia (http://www.research.digital.com). $\mathrm{O}$ atendimento "on-line" (no "site" da Amazon) demora apenas alguns segundos para ser realizado, dependendo do horário do acesso.

Percebe-se que as organizações pesquisadas estão efetivamente próximas de seus mercados. O AltaVista estende seu alcance a usuários de todo o mundo (http://www. AltaVista.digital.com/av/content/av_network.html). A Amazon compromete-se a entregar encomendas para residentes em mais de 160 países.

Quanto ao suporte de atendimento para continuidade da relação fornecedor/cliente, como pós venda, registro para novas ofertas, reforço de oferta, promoções, etc., constata-se que o AltaVista oferece vários serviços adicionais aos usuários, além da pesquisa por palavras (http://www.altavista.digital.com).

O cliente pode escrever seus comentários, sugestões e questões para searchsupport@altavista.com. Para uma resposta mais efetiva, o usuário deve indicar se deseja uma resposta e fornecer seu "e-mail", URL e endereço da página em que estava quando notou um erro ou quis dar uma sugestão. Para problemas de ordem técnica, é necessário dizer qual navegador, versão e plataforma o usuário utiliza, assim como uma descrição detalhada do problema. 
Para a Amazon, o atendimento ao cliente está apenas começando quando este adquire um livro. Assim que efetua uma compra, passa a fazer parte do cadastro da loja, onde figuram todos os seus dados pessoais, além da listagem de itens comprados, andamento dos pedidos e cartão utilizado no pagamento. A organização também fornece, periodicamente, novas sugestões de compra, baseadas no gosto individual de cada cliente (todas estas informações constam no banco de dados). Se o cliente desejar, poderá requisitar outros serviços personalizados. Em caso de qualquer dúvida, o cliente pode enviar um "email" para o serviço de atendimento da Amazon.

Pelas características acima descritas, pode-se constatar que ambas as organizações tratam o cliente de forma bastante individualizada, estando próximas do que se poderia chamar de estratégia de segmentação absoluta (nicho de um só). O quadro 4 apresenta os resultados obtidos para a categoria analítica "atendimento ao cliente". 


\begin{tabular}{|c|c|c|c|}
\hline ITEM & $\begin{array}{c}\text { CASO } \\
\text { ALTAVISTA }\end{array}$ & CASO AMAZON & OBSERVAÇÕES \\
\hline \multicolumn{4}{|c|}{ Atendimento ao cliente } \\
\hline $\begin{array}{l}\text { Como funciona o } \\
\text { sistema de atendi- } \\
\text { mento ao cliente? }\end{array}$ & $\begin{array}{l}\text { O cliente deve conec- } \\
\text { tar-se ao "site" da em- } \\
\text { presa, efetuar a pesqui- } \\
\text { sa através de palavras, } \\
\text { frases ou expressões e } \\
\text { verificar os resultados }\end{array}$ & $\begin{array}{l}\text { O cliente deve conectar-se } \\
\text { ao "site" da empresa, na- } \\
\text { vegar nas páginas de pro- } \\
\text { dutos que deseja pesquisar } \\
\text { ou adquirir e efetuar a } \\
\text { compra }\end{array}$ & $\begin{array}{l}\text { O atendimento é ágil } \\
\text { e simplificado em } \\
\text { ambas as organiza- } \\
\text { ções }\end{array}$ \\
\hline $\begin{array}{l}\text { Quais } \\
\text { utiliza }\end{array}$ & Internet & Internet, correio e fax & \\
\hline $\begin{array}{l}\text { Quais as principais } \\
\text { características da } \\
\text { operação? }\end{array}$ & $\begin{array}{l}\text { Facilidade de acesso, } \\
\text { alta velocidade de res- } \\
\text { posta, interatividade, } \\
\text { dinamismo, grande a- } \\
\text { brangência }\end{array}$ & $\begin{array}{l}\text { Facilidade de acesso, faci- } \\
\text { lidade de pesquisa, grande } \\
\text { variedade, preços re- } \\
\text { duzidos, personalização } \\
\text { dos serviços }\end{array}$ & $\begin{array}{l}\text { A facilidade de a- } \\
\text { cesso e de pesquisa } \\
\text { são características } \\
\text { comuns a OV }\end{array}$ \\
\hline $\begin{array}{l}\text { Qual a confiabili- } \\
\text { dade do produto ou } \\
\text { serviço? }\end{array}$ & $\begin{array}{l}\text { Atualização mensal do } \\
\text { índice, visita diária das } \\
\text { URL registradas, exclu- } \\
\text { são dos "links" mortos } \\
\text { e páginas duplicadas } \\
\end{array}$ & $\begin{array}{l}\text { É possível verificar o an- } \\
\text { damento do pedido; tran- } \\
\text { sações com cartão de cré- } \\
\text { dito são criptografadas pa- } \\
\text { ra maior segurança }\end{array}$ & $\begin{array}{l}\text { A OV é baseada em } \\
\text { confiança }\end{array}$ \\
\hline $\begin{array}{l}\text { O atendimento fa- } \\
\text { cilita a escolha do } \\
\text { produto ou serviço? }\end{array}$ & $\begin{array}{l}\text { Sim, a página tem de- } \\
\text { sign atraente e é bem } \\
\text { organizada }\end{array}$ & $\begin{array}{l}\text { Sim, a página tem design } \\
\text { atraente e é bem organiza- } \\
\text { da }\end{array}$ & $\begin{array}{l}\text { O "site" } \\
\text { a compra } \\
\text { quisa do } \\
\end{array}$ \\
\hline $\begin{array}{l}\mathrm{O} \text { atendimento ofe- } \\
\text { rece alternativas de } \\
\text { custos? }\end{array}$ & Não aplicável & $\begin{array}{l}\text { Não em relação ao produ- } \\
\text { to, mas o valor da taxa de } \\
\text { entrega pode variar }\end{array}$ & \\
\hline $\begin{array}{l}\text { Existem alternati- } \\
\text { vas de formas de } \\
\text { pagamento? }\end{array}$ & Não aplicável & $\begin{array}{l}\text { O pagamento é feito sem- } \\
\text { pre com cartão de crédito }\end{array}$ & $\begin{array}{l}\text { Por enquanto, a ú- } \\
\text { nica forma de paga- } \\
\text { mento possível é por } \\
\text { cartão }\end{array}$ \\
\hline $\begin{array}{l}\text { O atendimento é } \\
\text { capaz de propor al- } \\
\text { ternativas? }\end{array}$ & $\begin{array}{l}\text { Sim, o serviço sempre } \\
\text { apresenta todos os re- } \\
\text { sultados encontrados }\end{array}$ & $\begin{array}{l}\text { Sim, a empresa sugere no- } \\
\text { vas opções de compra re- } \\
\text { gularmente }\end{array}$ & $\begin{array}{l}\text { Sempre são ofereci- } \\
\text { das diferentes alter- } \\
\text { nativas ao cliente }\end{array}$ \\
\hline $\begin{array}{l}\text { O tempo de respos- } \\
\text { ta é rápido o bas- } \\
\text { tante para encantar } \\
\text { o cliente? }\end{array}$ & $\begin{array}{l}\text { Sim, o tempo é medido } \\
\text { em frações de segundos }\end{array}$ & $\begin{array}{l}\text { Sim, mas em alguns casos } \\
\text { a taxa cobrada pode ser } \\
\text { bastante alta }\end{array}$ & $\begin{array}{l}\text { A diferença de tem- } \\
\text { po deve-se à nature- } \\
\text { za do produto (virtu- } \\
\text { al ou não) }\end{array}$ \\
\hline
\end{tabular}

Quadro 4: Atendimento ao cliente nas OV - Parte B 


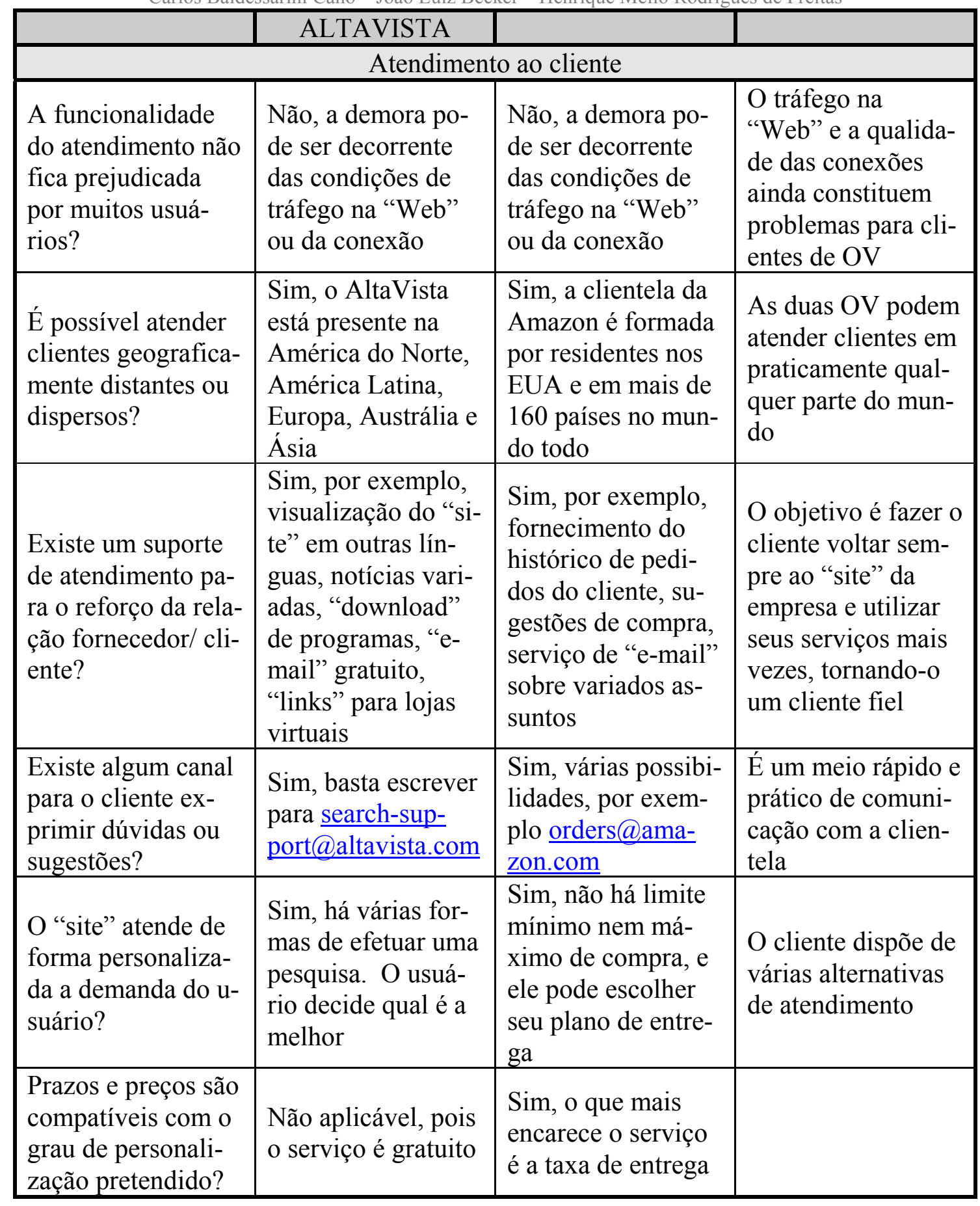

\section{Fractalidade}




\section{GESTÃO DA INFORMAÇÃO - ORGANIZAÇÕES NO ESPAÇO CIBERNÉTICO: ESTUDO COMPARATIVO ALTAVISTA E AMAZON BOOKS \\ Carlos Baldessarini Cano - João Luiz Becker - Henrique Mello Rodrigues de Freitas}

Por fractalidade entende-se a capacidade de atendimento da OV reproduzir-se indefinidamente no tempo e no espaço. Alguns autores chamam esta característica de ubiqüidade (McKenna, 1997). Com a finalidade de investigar esta característica nas organizações pesquisadas, buscaram-se evidências sobre a dispersão geográfica de seus serviços. Percebe-se claramente que tanto o AltaVista como a Amazon estendem seu alcance a usuários afastados de suas bases físicas. Este afastamento, entretanto, não é percebido pelo cliente, pois a funcionalidade de atendimento é sempre a mesma. Para qualquer cliente, os únicos requisitos para utilizar os serviços da Alta Vista e da Amazon são um computador com modem, um "browser" (navegador), uma linha telefônica e um provedor de acesso. Desta forma, a expansão dos limites de atendimento das organizações não requer aumento de suas instalações físicas.

De outra parte, é importante ressaltar que a distribuição dos livros (físicos) é um processo não virtualizado (ainda) na Amazon Books. Como conseqüência, não se percebe fractalidade nesta operação. Há diferenças marcantes de serviços (preços, prazos, taxas, por exemplo) para clientes localizados em diferentes países. Em vista disto, alguns autores afirmam que não demorará muito para que um bom número de autores passem a oferecer seus trabalhos eletronicamente, através de organizações como a Amazon (Peppers e Rogers, 1997). O quadro 5 sintetiza os resultados obtidos para a categoria analítica "fractalidade".

Quadro 5: Fractalidade nas OV

\begin{tabular}{|l|l|l|l|}
\hline \multicolumn{1}{|c|}{ ITEM } & \multicolumn{1}{|c|}{$\begin{array}{c}\text { CASO } \\
\text { ALTAVISTA }\end{array}$} & CASO AMAZON & OBSERVAÇÕES \\
\hline \multicolumn{4}{|c|}{ Fractalidade } \\
\hline $\begin{array}{l}\text { O empreendimento } \\
\text { tem facilidade para } \\
\text { atender o cliente } \\
\text { geograficamente } \\
\text { distante? }\end{array}$ & $\begin{array}{l}\text { Sim, ele oferece in- } \\
\text { terface na lingua- } \\
\text { gem nativa do usu- } \\
\text { ário, adaptado para } \\
\text { serviços locais de } \\
\text { Internet }\end{array}$ & $\begin{array}{l}\text { Sim, a diferença é } \\
\text { que este cliente de- } \\
\text { verá pagar uma ta- } \\
\text { xa de entrega mais } \\
\text { cara }\end{array}$ & $\begin{array}{l}\text { As duas OV podem } \\
\text { atender clientes em } \\
\text { praticamente qual- } \\
\text { quer parte do mun- } \\
\text { do }\end{array}$ \\
\hline $\begin{array}{l}\text { O empreendimento } \\
\text { pode ampliar seus } \\
\text { limites geográficos } \\
\text { com facilidade? }\end{array}$ & $\begin{array}{l}\text { Sim, pois a expan- } \\
\text { são não requer au- } \\
\text { mento das instala- } \\
\text { ções físicas }\end{array}$ & $\begin{array}{l}\text { Sim, mas depen- } \\
\text { dendo do pais, a } \\
\text { entrega pode demo- } \\
\text { rar até três meses }\end{array}$ & $\begin{array}{l}\text { As duas OV podem } \\
\text { atender clientes em } \\
\text { praticamente qual- } \\
\text { quer parte do mun- } \\
\text { do }\end{array}$ \\
\hline
\end{tabular}

\section{Confiança}

Pode-se afirmar que o produto ou serviço oferecido por ambas as organizações é confiável, ou seja, é completo e de boa qualidade, sendo constantemente aperfeiçoado. Em função dos números apresenta- 


\section{GESTÃO DA INFORMAÇÃO - ORGANIZAÇÕES NO ESPAÇO CIBERNÉTICO: ESTUDO COMPARATIVO ALTAVISTA E AMAZON BOOKS \\ Carlos Baldessarini Cano - João Luiz Becker - Henrique Mello Rodrigues de Freitas}

dos, os clientes sentem-se absolutamente confiantes nas organizações. De fato, o número de páginas indexadas no AltaVista atinge cerca de 140 milhões, em 25 línguas, por toda a Internet, apresentando todos os documentos que contenham a palavra, frase ou expressão desejada. Além disto, o Scooter está constantemente varrendo a rede, indexando novas páginas e eliminando "links" mortos e páginas duplicadas. Da parte da Amazon, são mais de 4 milhões de títulos em catálogo, abrangendo praticamente tudo o que se publica no mundo inteiro. O número de clientes não para de crescer. O quadro 6 demonstra os resultados obtidos para a categoria analítica "confiança".

Quadro 6: Confiança nas OV

\begin{tabular}{|l|l|l|l|}
\hline \multicolumn{1}{|c|}{ ITEM } & \multicolumn{1}{|c|}{$\begin{array}{c}\text { CASO } \\
\text { ALTAVISTA }\end{array}$} & CASO AMAZON & OBSERVAÇÕES \\
\hline \multicolumn{4}{|c|}{ Confiança } \\
\hline $\begin{array}{l}\text { O produto ou ser- } \\
\text { viço apresentado é } \\
\text { de boa qualidade? }\end{array}$ & $\begin{array}{l}\text { O AltaVista ras- } \\
\text { treia 140 milhões } \\
\text { de páginas em 25 } \\
\text { línguas, tem seus } \\
\text { dados atualizados } \\
\text { constantemente e } \\
\text { responde rapida- } \\
\text { mente }\end{array}$ & $\begin{array}{l}\text { O cliente compra e- } \\
\text { xatamente o que } \\
\text { deseja, pode verifi- } \\
\text { car o andamento do } \\
\text { seu pedido e tem a- } \\
\text { cesso a serviços } \\
\text { personalizados }\end{array}$ & $\begin{array}{l}\text { Em ambas as em- } \\
\text { presas o serviço é } \\
\text { amplo e de boa } \\
\text { qualidade }\end{array}$ \\
\hline $\begin{array}{l}\text { O produto ou ser- } \\
\text { viço é constante- } \\
\text { mente aperfeiçoado } \\
\text { e atualizado? }\end{array}$ & $\begin{array}{l}\text { Sim, o indexador } \\
\text { busca novas pági- } \\
\text { nas e elimina } \\
\text { "links" mortos dia- } \\
\text { riamente }\end{array}$ & $\begin{array}{l}\text { Sim, a empresa a- } \\
\text { companha os lança- } \\
\text { mentos de todos os } \\
\text { produtos que co- } \\
\text { mercializa }\end{array}$ & $\begin{array}{l}\text { A atualização é } \\
\text { imprescindível em } \\
\text { organizações como } \\
\text { estas }\end{array}$ \\
\hline
\end{tabular}

\section{Aprendizado organizacional}

A estratégia de aprendizado organizacional do AltaVista tem sido, desde o início, uma prospecção bastante aberta de conhecimento, para além das fronteiras da organização. O ponto de partida foi um núcleo básico de três especialistas, vindos de diferentes laboratórios da Digital. À medida em que o projeto ia se desenvolvendo e requisitando conhecimentos mais específicos, vários pesquisadores de outros laboratórios e mesmo de diferentes países foram chamados a participar do empreendimento. A tecnologia de rede do sistema, a criação da categorização dinâmica e o desenvolvimento da tecnologia de etiquetas de linguagem são contribuições destes pesquisadores. Ao longo de todo o projeto, conhecimentos específicos foram localizados e agregados, à medida em que se tornavam necessários. Isto funcionou sem a necessidade de uma equipe convencionalmente constituída em uma base física única.

No caso estudado, faz-se necessário notar que uma parte importante do conhecimento organizacional é acumulada, operada e disponibilizada por um conjunto de computadores e "softwares": a interface de pesquisa, o mecanismo de pesquisa, o rastreador (Scooter), o indexador da rede (Vista), o indexador de notícias e o servidor de notícias.

A busca de novas fontes de conhecimento ocorre por meio de intenso intercâmbio com instituições de pesquisa espalhadas pelo mundo. Quanto à investigação de novas fontes de conhecimento para agrega- 


\section{GESTÃO DA INFORMAÇÃO - ORGANIZAÇÕES NO ESPAÇO CIBERNÉTICO: ESTUDO COMPARATIVO ALTAVISTA E AMAZON BOOKS \\ Carlos Baldessarini Cano - João Luiz Becker - Henrique Mello Rodrigues de Freitas}

ção ao seu banco de dados, esta é feita de forma contínua e ininterrupta pelos mecanismos de busca, indexação e armazenamento, conforme já descrito.

Também a Amazon pode ser caracterizada como uma organização de aprendizado. Inicialmente constituída por somente uma pessoa, seu fundador, à medida em que o negócio foi crescendo e atraindo clientes, o quadro funcional foi aumentando, chegando aos atuais 2.000 funcionários. A Amazon afirma que sua filosofia é simples: trabalhe muito, divirta-se e faça história. Esta última, segundo seu presidente, é a razão mais forte para alguém querer trabalhar na empresa: ela está construindo algo sem precedentes, criando um novo modelo de corporação. Busca-se a inovação em todas as áreas.

Como no caso do AltaVista, faz-se necessário notar que uma parte importante do conhecimento organizacional é acumulada, operada e disponibilizada por um conjunto de computadores e "softwares". Todas as informações sobre os clientes (dados pessoais, compras efetuadas, perfil de consumo) são arquivadas no banco de dados da empresa.

A Amazon emprega principalmente três maneiras de obter novas fontes de conhecimento. Primeiramente, ela mantém anúncios de empregos e estágios no seu "site" na Internet, para cargos variados. Em segundo lugar, ela mantém um programa de empresas associadas, adquirindo aquelas que podem facilitar a sua expansão. Finalmente, ela possui um vasto banco de dados com o os dados pessoais, pedidos efetuados, preferências e perfil de compra de todos os seus seis milhões de clientes. Estas informações são automaticamente gravadas quando o cliente se cadastra no "site" da empresa, e constituem uma fonte valiosa de conhecimento. O quadro 7 sintetiza os resultados obtidos para a categoria analítica "aprendizado organizacional".

Quadro 7: Aprendizado organizacional nas OV

\begin{tabular}{|l|l|l|l|}
\hline \multicolumn{1}{|c|}{ ITEM } & \multicolumn{1}{|c|}{$\begin{array}{c}\text { CASO } \\
\text { ALTAVISTA }\end{array}$} & CASO AMAZON & OBSERVAÇÕES \\
\hline \multicolumn{3}{|c|}{ Aprendizado organizacional } \\
\hline $\begin{array}{l}\text { Como a organiza- } \\
\text { ção desenvolve in- } \\
\text { ternamente o a- } \\
\text { prendizado organi- } \\
\text { zacional? }\end{array}$ & $\begin{array}{l}\text { Por meio de uma pros- } \\
\text { pecção bastante aberta do } \\
\text { conhecimento (sem equi- } \\
\text { pe convencionalmente } \\
\text { constituída numa base fí- } \\
\text { sica única) }\end{array}$ & $\begin{array}{l}\text { Por meio da busca } \\
\text { constante da inova- } \\
\text { ção, do trabalho em } \\
\text { equipe e da estimula- } \\
\text { ção da criatividade } \\
\text { de todos os funcio- } \\
\text { nários }\end{array}$ & $\begin{array}{l}\text { O trabalho em equipe e a } \\
\text { criatividade são muito } \\
\text { valorizados }\end{array}$ \\
\hline $\begin{array}{l}\text { Como a organiza- } \\
\text { ção investiga o } \\
\text { ambiente externo } \\
\text { em busca de novas } \\
\text { fontes de conheci- } \\
\text { mento? }\end{array}$ & $\begin{array}{l}\text { Via Internet, por meio de } \\
\text { intenso intercâmbio com } \\
\text { instituições de pesquisa } \\
\text { espalhadas pelo mundo e } \\
\text { do seu banco de dados }\end{array}$ & $\begin{array}{l}\text { Via Internet e por } \\
\text { meio de empresas } \\
\text { associadas à Ama- } \\
\text { zon, bem como do } \\
\text { seu banco de dados }\end{array}$ & $\begin{array}{l}\text { A Internet desempenha } \\
\text { um papel importante na } \\
\text { investigação do ambiente } \\
\text { externo }\end{array}$ \\
\hline
\end{tabular}

\section{CONSIDERAÇÕES FINAIS}

Este trabalho objetivou aprofundar a análise da OV, realizando estudos de caso em duas organizações que se salientam no cenário internacional como significativos exemplos de OV: o serviço de busca automática AltaVista (http://www.altavista.digital. com) e a livraria virtual Amazon Books 
(http://www.amazon.com). Tal estudo objetiva verificar em que medida as propaladas características da OV se fazem efetivamente presentes nestas organizações.

Ao final destes estudos de casos, algumas considerações devem ser registradas, bem como limitações e recomendações importantes. O trabalho buscou verificar a ocorrência de aspectos inovadores, exteriorizados por organizações ditas virtuais, que compõem um cenário inédito em consolidação. Muitos destes aspectos estão em desenvolvimento, ainda incompletos, seja sob o enfoque tecnológico ou de aplicação, e, portanto, em constante dinâmica de mudanças. Tal dinâmica em nada favorece a cristalização de conceitos, a consolidação de normas e procedimentos, bem como uma correta avaliação do que está sendo analisado.

Das organizações estudadas, sem dúvida a mais caracterizadamente virtual é o serviço de busca automática AltaVista. Não somente seus processos são completamente virtualizados, como seu próprio produto, puramente informacional. Por outro lado, a livraria virtual Amazon Books, embora com seus processos altamente virtualizados, ainda depende da logística tradicional para a distribuição de seu produto, o livro, ainda físico. Isto não causa surpresa, na medida em que nenhuma organização é totalmente virtual, pois sempre haverá uma base tecnológica concreta que lhe dê suporte. Mais corretamente, deve-se falar em graus de virtualização. É possível, conforme especulam diversos autores, que o próprio suporte físico do livro venha a sofrer modificações substanciais.

É claro que, se a livraria virtual Amazon Books entregasse livros eletrônicos, poderia avançar mais no processo de virtualização, pois o livro virtual permite uma entrega também virtualizada. Um concorrente da livraria virtual Amazon Books, a livraria Barnes \& Nobles, já vende e entrega livros eletrônicos via Internet.

Uma figura bidimensional é, por definição, insuficiente para mostrar com clareza a complexidade resultante da junção de vários níveis de virtualização em uma organização. No entanto, tenta-se, na figura 1, delinear o contraste de uma estruturação convencional em relação à virtual.

\section{Figura 1: Topografia da virtualidade}

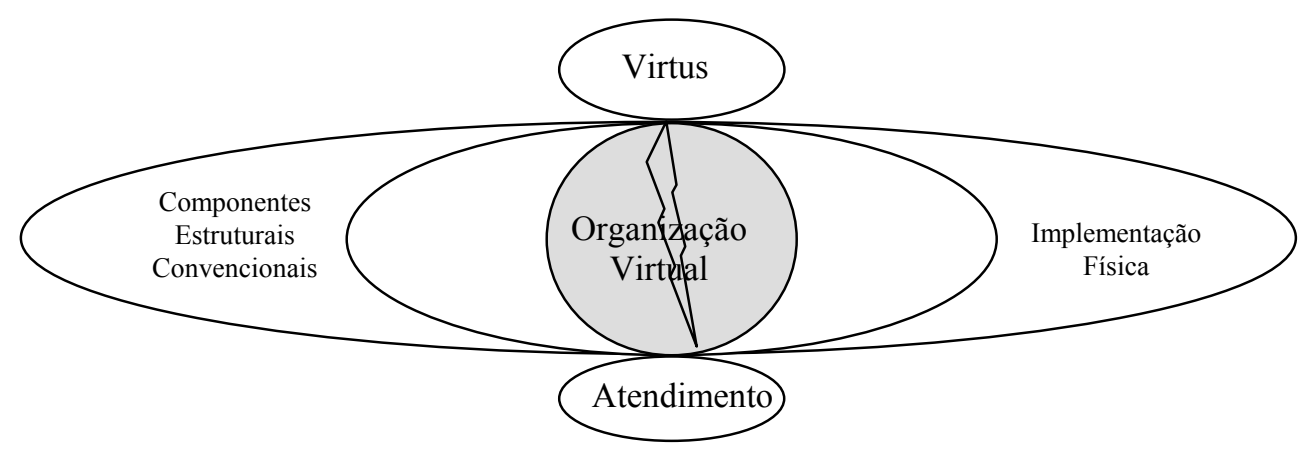

As curvas ligando o topo ao pé da figura representam as estruturas físicas que necessitam ser utilizadas para o atendimento das demandas dos clientes das organizações. A completa virtualização da organização atalha as estruturas físicas (representada pelo raio ligando o topo ao pé da figura 1), indicando o imediato atendimento de uma demanda com um mínimo de materialidade e sem a estruturação física convencional, reduzindo a organização a um ponto de dimensão infinitamente pequena. Dependendo 


\section{GESTÃO DA INFORMAÇÃO - ORGANIZAÇÕES NO ESPAÇO CIBERNÉTICO: ESTUDO COMPARATIVO ALTAVISTA E AMAZON BOOKS \\ Carlos Baldessarini Cano - João Luiz Becker - Henrique Mello Rodrigues de Freitas}

do seu grau de materialidade, os processos tendem a exercer uma expansão vertical e horizontal, inchando os contornos da organização. Quanto mais extensos e materiais, mais afastados estão do centro, um ponto adimensional. Novamente, reforça-se a afirmação de que esta é uma situação idealizada, um modelo teórico de $\mathrm{OV}$, não encontrado de fato na prática.

De um modo geral, a literatura sobre OV, corporações virtuais e o processo de virtualização das estruturas de produção e de administração é ainda incipiente e não pode ser considerada consolidada e estruturada. Esta fragilidade de referencial bibliográfico, e acelerada dinâmica conferem grande validade ao método de estudo de casos, pois estes registram aspectos importantes de um dado momento da organização. Se refeitos em alguns meses, certamente os estudos de caso da Amazon e do AltaVista mostrarão outros resultados, pois as organizações, o mercado, o cenário de utilização das tecnologias, as própria tecnologias e a cultura do público serão diferentes. Por exemplo, a Amazon poderá não mais ser vista como uma livraria virtual, tão somente, mas como um portal multi-serviços, dando acesso a muitas outras portas.

Este panorama de acelerada inovação produz uma grande riqueza de assuntos passíveis de novas investigações, muitos anotados para futuro aprofundamento. Se percorrida a teoria administrativa clássica, um grande número de temas surgem com possibilidades de redefinição operacional e estratégica, quando colocados sob a luz da virtualização (Ware et al., 1997; Barabba, 1998; Davis e Meyer, 1999; Gates, 1999). Aspectos inéditos (muitas vezes surpreendentes), surgem com freqüência, alguns provocando uma reflexão profunda, para o entendimento do fenômeno em si e de suas conseqüências. Um novo cenário está em construção, para a Administração e para as organizações. Na verdade, um novo paradigma emerge.

\section{NOTA}

Os autores agradecem as contribuições e críticas feitas pelos revisores anônimos e incorporadas neste trabalho. A pesquisa que deu origem a este artigo foi parcialmente financiada pelo CNPq e pela FAPERGS, o que os autores agradecem.

\section{Artigo recebido em 02.04.2000. Aprovado em 10.07.2001.}

\section{REFERÊNCIAS BIBLIOGRÁFICAS}

BARABBA, V.P. Revisiting Plato's cave: business design in an age of uncertainty. In TAPSCOTT, D. (ed.). Blueprint to the Digital Economy. New York: McGraw-Hill, 1998, 410p.

BENEDIKT, M. Cyberspace: some proposals. Cyberspace. 1994.

$<$ http://virtual.park.uga.edu/ hypertxt/cyberspace $>$

BJUR, W. e CARAVANTES, G.R. Reengenharia ou Readministração?. Porto Alegre: AGE, 1994, $187 \mathrm{p}$

BYRNE, J.A. e BRANDT, R. The virtual corporation. Business Week. Fevereiro, 8, 1993, p. 99-103.

CANO, C.B.; BECKER, J.L. e FREITAS, H.M.R. Organização virtual e tecnologia da informação. Organizações e Sociedade. 5(12), maio/agosto 1998, p. 17-35. 
DAVENPORT, T. The virtual and the physical. CIO Magazin, nov 1995, $<\mathrm{http}: / /$ www.cio.com/CIO/cio_11_15_95_dav>.

DAVIDOW, W.H. e MALONE, M.S. A Corporação Virtual. São Paulo: Pioneira, 1993, 271p.

DAVIS, S. e MEYER, C. Blur: a velocidade da mudança na economia integrada. Rio de Janeiro: Campus, 1999, 188p.

GATES, W. A Empresa na Velocidade do Pensamento com um sistema nervoso digital. São Paulo: Companhia das Letras, 1999, 444p.

HAZLETON, L. Jeff Bezos: how he built a billion dollar net worth before his company even turned a profit. Success. Julho, 1998, p. 58-60.

LÉVY, P. O que é o Virtual?. São Paulo: Editora 34, 1996, 157p.

McKENNA, R. Real Time: preparing for the age of the never satisfied customer. Boston: Harvard Business School Press, 1997. 204p.

MENDES, M.L. “O explorador”. Revista Exame. Abril 1999, p. 89-98.

PEPPERS, D. e ROGERS, M. Enterprise One to One: tools for competing in the interactive age. New York: Doubleday, 1997, 436p.

POZZEBON, M. e FREITAS, H.M.R. Pela aplicabilidade - com maior rigor científico - dos estudos de caso em sistema de informações. In: Encontro Nacional dos Programas de Pós-Graduação em Administração, 21. Rio das Pedras: ANPAD, 1997, Anais em CD-ROM.

RAY, E.J.; RAY, D.S. e SELTZER, R. The AltaVista Search Revolution. New York: McGraw-Hill, 1998. 395p.

RIDOUT, R. The virtual IT organization. Techweb News. 22/07/1997.

$<$ http://www.techweb.com/se/directlink/cgi?IWK19970922s0044>.

SKYRME, D. The neworked organization. 1995. <http://www.skyrme.com/insights/1network.htm>.

THOMPSON, C. Virtual office. Defense Advanced Research Projects Agency, 1997, $<$ http://www.objs.com/survey/vo.htm>.

WARE, J.; GEBAUER, J.; HARTMAN, A. e ROLDAN, M. The Search for Digital Excellence. New York: McGraw-Hill, 1997, 432p.

YIN, R.K. Case Study Research: design and methods. $2^{\text {nd }}$ ed. Thousand Oaks: Sage, 1994. 171p. 